\title{
In vitro and In vivo Study of Effect of $\alpha$-Adrenergic Agonist-Methyldopa on the Serum Biochemical Laboratory Findings
}

\section{Ibrahim Abdel Aziz Ibrahim ${ }^{1 *}$, Naiyer Shahzad ${ }^{1}$, Fawwaz S. Al-Joudi ${ }^{2}$, Saeed S. Al-Ghamdi ${ }^{1}$, Mustafa Ahmed Alshagga ${ }^{3}$ and Nehad M.} Hammodi ${ }^{4}$

${ }^{1}$ Department of Pharmacology and Toxicology, Faculty of Medicine, Umm Al-Qura University, Makkah, Saudi Arabia

${ }^{2}$ Royal College of Medicine Perak, University of Kuala Lumpur, Ipoh, Malaysia

${ }^{3}$ Newcastle University Medicine Malaysia, Kota IImu, Educity@Iskandar, Nusajaya, 79200, Johor, Malaysia

${ }^{4}$ Department of Clinical Laboratory Science, College of Pharmacy, Baghdad University, Baghdad, Iraq

\begin{abstract}
Objectives: The effects of the antihypertensive drug methyldopa on biochemical laboratory findings were monitored both in vitro and in vivo particularly those of metabolites and enzymes which are routinely requested by physicians.

Methods: In vitro and in vivo studies were performed. For the in vitro study, solutions of methyldopa concentrations were prepared according to its maximum serum concentration as reported in the literature and were added to blank, normal serum. The samples were then analyzed in parallel with a standard test using the same laboratory techniques. For the in vivo study, blood was collected before starting and two weeks after starting methyldopa therapy from 40 subjects that were newly diagnosed with essential hypertension. The control sera were collected from 30 healthy volunteers of comparable ages. The samples were analyzed for glucose, Total Protein (TP), urea, creatinine, Total Cholesterol (TC), Triglyceride (TG), Aspartate Transaminase (AST), Alanine Transaminase (ALT), Lactate Dehydrogenase (LDH) and Creatine Kinase (CK).

Results: In the in vitro study, methyldopa induced a decrease in the readings of serum glucose, TP, urea, TC, AST, $\mathrm{ALT}$, and CK, whereas the LDH levels recorded an increase. In vivo study of methyldopa leads to increase the levels of serum glucose, TP, urea, TC, TG, AST, ALT and LDH.

Conclusions: Methyldopa induced significant alterations in the in vitro as well as in the in vivo measurements. These alterations are required to be taken seriously by physicians to avoid misinterpretations of data generated during routine practice. All the in vitro changes in biochemical parameters are a result of chemical or physical reactions, whereas the in vivo changes resulted mostly from physiological or metabolic factors.
\end{abstract}

Keywords: Methyldopa; Serum biochemical parameters; Physiological or Metabolic factors

\section{Introduction}

Methyldopa is an $\alpha$-adrenergic agonist (selective for $\alpha_{2}$-adrenergic receptors) psychoactive drug used as a central sympatholytic agent that is used to reduce hypertension [1,2]. It is L- $\alpha$-Methyl-3,4dihydroxyphenylalanine $\left(\mathrm{C}_{10} \mathrm{H}_{13} \mathrm{NO}_{4}\right)$ [3]. It has been produced under a number of commercial names including Aldomet, Aldoril, Dopamet and Dopegyt. Methyldopa is colorless or almost colorless crystals or a white to yellowish-white colorless fine powder, which may contain friable lumps [4]. Methyldopa is slightly soluble in water, very slightly soluble in ethanol (96\%); practically insoluble in chloroform and ether. It is freely soluble in dilute mineral acids [3]. The drug crosses the placental barrier, appears in cord blood, and breast milk. The maximum serum concentration $\left(\mathrm{C}_{\max }\right)$ after an oral administration of $250 \mathrm{mg}$ of methyldopa is $975 \mathrm{ng} / \mathrm{ml}$. It is given as an oral suspension of $50 \mathrm{mg} / \mathrm{ml}$, or in tablets of $125 \mathrm{mg}, 250 \mathrm{mg}$ or $500 \mathrm{mg}$, in addition to 50 $\mathrm{mg} / \mathrm{ml}$ injection $[5,6]$.

Methyldopa is decarboxylated in the Central Nervous System (CNS) to $\alpha$-methyl-noradrenaline, which stimulates $\alpha_{2}$-adrenoceptors resulting in a reduction in sympathetic tone and a fall in blood pressure. Methyldopa reduces tissue concentrations of dopamine, nor adrenaline, adrenaline, and serotonin [4,6].

Although the use of methyldopa has declined because of its side effects, and especially following the introduction of safer drugs, it is still in use in cases of untreatable hypertension and in gestational hypertension, known as Pregnancy-Induced Hypertension (PIH). A single oral dose can produce a maximum effect within 4-6 hours although the maximum hypotensive effect may not occur until the second day of continuous treatment [4]

Methyldopa is used in the treatment of moderate to severe hypertension usually in combination with a diuretic or a beta-blocking agent. It reduces both the standing and the supine blood pressure. The initial oral dose is equivalent to $250 \mathrm{mg}$ of anhydrous methyldopa two or three times daily for two days [4].

The direct effects of in vivo methyldopa administration exhibited a $25 \%$ reduction in intrasynaptosomal $5-\mathrm{HT}$ and a $15 \%$ reduction in 5-HT synthesis when compared to synaptosomes from saline-treated animals. In addition a $15 \%$ reduction in synaptosomal tryptophan levels was observed [7]. According to Chatelain et al. [8] $\alpha$-methydopa treatment increases the number of $\beta$-adrenoceptors by $20-32 \%$ and the maximal response of adenylate cyclase activity to $\beta$-blockers. Methyldopa treatment significantly affects clinical chemistry tests at five times the upper end of their therapeutic ranges on the following

*Corresponding author: Dr. Ibrahim Abdel Aziz Ibrahim, Department of Pharmacology and Toxicology Faculty of Medicine, Umm Al-Qura University, Makkah 21955 Saudi Arabia P.O. Box: 7607, Tel: (+966) 580030 119; Fax: (+9662)5667 874; E-mail: jjurishi@yahoo.com

Received September 24, 2013; Accepted October 22, 2013; Published October 29, 2013

Citation: Ibrahim IAA, Shahzad N, Al-Joudi FS, Al-Ghamdi SS, Alshagga MA, et al. (2013) In vitro and In vivo Study of Effect of a-Adrenergic Agonist-Methyldopa on the Serum Biochemical Laboratory Findings. Clin Exp Pharmacol 3: 136. doi:10.4172/2161-1459.1000136

Copyright: (C) 2013 Aziz Ibrahim IA, et al. This is an open-access article distributed under the terms of the Creative Commons Attribution License, which permits unrestricted use, distribution, and reproduction in any medium, provided the original author and source are credited. 
tests: glucose, bilirubin, carbon dioxide, calcium, cholesterol, uric acid and aspartate aminotransferase [9].

The present study was undertaken to evaluate the effects of the antihypertensive drug methyldopa on biochemical laboratory findings that were monitored both in vitro and in vivo, particularly those of blood metabolites and enzymes, which are usually requested by physicians for professional diagnosis and for better understanding of their clinical importance.

\section{Materials and Methods}

\section{In vitro serum simulation test}

A stock solution was prepared by dissolving $30 \mathrm{mg}$ of methyldopa in $100 \mathrm{ml}$ of $0.1 \mathrm{~N} \mathrm{HCl}: 6.5 \mu \mathrm{l}$ of this solution represent $1950 \mathrm{ng} / \mathrm{ml}$. The stock solution was diluted to produce final concentrations of 1950, 975 and $487.5 \mathrm{ng} / \mathrm{ml}$, which represent the $\mathrm{C}_{\max }$ of the drug in serum following the administration of $500 \mathrm{mg}, 250 \mathrm{mg}$ and $125 \mathrm{mg}$, respectively. The negative control was mixed with solvent alone $(0.1 \mathrm{~N}$ $\mathrm{HCl})$. Serum were obtained from the methyldopa treated subjects and used to compare to control group.

Measured biochemical parameters included glucose, Total Protein (TP), urea, creatinine, Total Cholesterol (TC), Triglycerides (TG), Aspartate Aminotransferase (AST), Alanine Aminotransferase (ALT), Lactate Dehydrogenase (LDH) and Creatine Kinase (CK). These parameters were measured by using Randox kits (Randox Laboratories Ltd, United Kingdom), and read by spectrophotometry.

Net effect of drug on laboratory test $=$ Value $($ Serum + Drug $)-$ Value (Serum + Solvent)

\section{In vivo test}

An ethical approval was granted during the meeting of the Heads of Departments of the Pharmacy School in October 2002; and all patients were informed of the procedures and objectives of the study in advance.

Serum samples from 30 healthy subjects were used as controls. These control subjects were without evidence of hypertension and diabetes mellitus, and their ages ranged from 41 to 63 years to match with the test subjects. Similar biochemical parameters were measured and similar methods were utilized as those in the in vitro tests.

The study was conducted on sera from 40 patients (21 males and 19 females) aged 45-66 years, with Non-Insulin-Dependent Diabetes

\begin{tabular}{|c|c|c|c|c|}
\hline & Control & $500 \mathrm{mg}$ & $250 \mathrm{mg}$ & $125 \mathrm{mg}$ \\
\hline $\begin{array}{l}\text { Glucose } \\
\mathrm{mg} / \mathrm{dl}\end{array}$ & $94.33 \pm 16.5$ & $37.66 \pm 23.15^{*}$ & $52.33 \pm 26.1^{*}$ & $73 \pm 22.91^{*}$ \\
\hline TP g/l & $72 \pm 8.88$ & $51.33 \pm 6.5^{*}$ & $57.33 \pm 6.02^{*}$ & $66 \pm 6.55^{*}$ \\
\hline Urea mg/dl & $34.0 \pm 9.8$ & $15.0 \pm 4.5^{*}$ & $22.6 \pm 3.5^{*}$ & $27.0 \pm 4.3^{*}$ \\
\hline $\begin{array}{l}\text { Creatinine } \\
\mathrm{mg} / \mathrm{dl}\end{array}$ & $1.21 \pm 0.265$ & $1.13 \pm 0.253$ & $1.2 \pm 0.05$ & $1.29 \pm 0.274$ \\
\hline TC mg/dl & $175.66 \pm 51.54$ & $61.33 \pm 39.2^{*}$ & $76.33 \pm 42.19^{*}$ & $91 \pm 45.29^{*}$ \\
\hline TG mg/dl & $154.33 \pm 17.75$ & $36 \pm 19.97^{*}$ & $54.33 \pm 17.78^{*}$ & $69.33 \pm 13.31^{*}$ \\
\hline AST U/I & $16.33 \pm 6.5$ & $14.33 \pm 5.5$ & $12.56 \pm 3.66$ & $10.46 \pm 2.33$ \\
\hline ALT U/I & $12.66 \pm 8.5$ & $9.16 \pm 8.75$ & $11.5 \pm 9.26$ & $14.16 \pm 11.003$ \\
\hline CK IU/I & $117 \pm 46.60$ & $85.66 \pm 38.21$ & $89.66 \pm 38.37$ & $92.66 \pm 39.14$ \\
\hline LDH U/I & $168 \pm 22.6$ & $196 \pm 4.58$ & $187 \pm 9.16$ & $157.33 \pm 18.03$ \\
\hline
\end{tabular}

\section{*significant $(p<0.05)$}

TP: Total Protein; TC: Total Cholesterol; TG: Triglyceride; AST: Aspartate Transaminase; ALT: Alanine Transaminase; LDH: Lactate Dehydrogenase; CK: Creatine Kinase

Table 1: In vitro effect of methyldopa on laboratory findings.
Mellitus (NIDDM) and newly diagnosed with essential hypertension at Dr. Abdul Majeed Hospital, Baghdad. They were given a dosage of 250 mg methyldopa daily for two weeks, when the post-treatment blood samples were collected. Pre- and post-treatment venous blood samples were collected from each patient. Serum was aspirated from clotted blood after centrifugation.

Three readings were taken, one for the serum from controls and two serum samples from the study subjects, one was taken before the start of the treatment (pre-treatment) and the other one was taken two weeks after (post-treatment). These three readings were compared with each other controls with pre-treatment, pre- with post-treatment and controls with post-treatment values to monitor the altered readings and evaluate their significance.

\section{Statistical analyses}

The readings of the biochemical tests were expressed as the mean \pm SD. The differences in the mean of tested parameters were examined by Student's T-test and P values less than 0.05 were taken as significant. The effects of different concentrations of methyldopa on biochemical parameters were evaluated by ANOVA.

\section{Results}

\section{Effects of methyldopa on in vitro biochemical laboratory findings}

Methyldopa, in vitro, has significantly reduced $(\mathrm{P}<0.05)$ the concentrations of glucose, TP, urea, TC and TG. These reductions appeared to be dose dependent. CK was also reduced in a similar pattern, but the reductions were not significant $(P>0.05)$. ALT readings were also reduced, non-significantly $(\mathrm{P}>0.05)$ though there was nonsignificant increase $(\mathrm{P}>0.05)$ above the control, in the readings obtained with sera treated with a low dose of $125 \mathrm{mg}$ methyldopa. While there was nonsignifant $(\mathrm{P}>0.05)$ reduction in AST values in a dose-dependent manner with a nonsignificant rise in the readings above the control for lower dose of $125 \mathrm{mg}$. Creatinine readings were not significantly altered. LDH showed a dose-dependent pattern of reduction. The $\mathrm{LDH}$ readings were elevated with the higher doses of 500 and $250 \mathrm{mg}$, and slightly reduced dose of $125 \mathrm{mg}$ (Table 1).

\section{Effects of methyldopa on in vivo biochemical laboratory findings}

The in vivo effects of methyldopa were measured in a different way. Some alterations were obtained in the readings of the biochemical parameters following the methyldopa therapy. Glucose was increased in both the pre- and post-treatment sera, though the increases were not significant $(\mathrm{P}>0.05)$. Urea, TC, AST and ALT all had the readings increased in the post-treatment sera only the increase of the AST was significant $(\mathrm{P}<0.05)$. Furthermore, there were significant $(\mathrm{P}<0.05)$ elevations in the readings of TG and $\mathrm{LDH}$ in the post-treatment sera. Creatinine was unaltered. The readings of TP were reduced in the pre-treatment sera whereas they were elevated in the post-treatment sera. The readings were reduced following the methyldopa treatment, although in the pre-treatment sera the reductions appeared to be significant $(\mathrm{P}<0.05)($ Table 2).

\section{Discussion}

The in vitro study of methyldopa has yielded some important findings whereby alterations in the readings of panel of tests have been obtained. Except for creatinine and LDH, all the other parameters tested gave reduced readings, most of which were significant (glucose, 


\begin{tabular}{|l|l|l|l|}
\hline & Control & Pre-treatment & Post-treatment \\
\hline Glucose mg/dl & $93.562 \pm 18.402$ & $102.70 \pm 19.562$ & $112.600 \pm 39.044$ \\
\hline TP g/l & $75.75 \pm 8.434$ & $69.40 \pm 7.904$ & $79.30 \pm 11.005^{\mathrm{b}}$ \\
\hline Urea mg/dl & $32.6 \pm 10.9$ & $32.9 \pm 9.3$ & $40.6 \pm 13.0$ \\
\hline $\begin{array}{l}\text { Creatinine } \\
\text { mg/dl }\end{array}$ & $1.113 \pm 0.255$ & $1.110 \pm 0.218$ & $1.253 \pm 0.143$ \\
\hline TC mg/dl & $191.437 \pm 34.298$ & $189.00 \pm 70.63$ & $215.40 \pm 84.417$ \\
\hline TG mg/dl & $123.06 \pm 32.947$ & $167.70 \pm 49.349^{\mathrm{a}}$ & $189.80 \pm 41.651^{\mathrm{c}}$ \\
\hline AST U/I & $22.937 \pm 6.884$ & $23.40 \pm 9.395$ & $30.00 \pm 8.856^{\mathrm{c}}$ \\
\hline ALT U/I & $18.375 \pm 6.365$ & $16.20 \pm 8.495$ & $23.20 \pm 14.195$ \\
\hline LDH U/I & $130.50 \pm 33.091$ & $142.70 \pm 31.478$ & $169.20 \pm 28.389^{\mathrm{c}}$ \\
\hline CK IU/I & $131.75 \pm 33.914$ & $100.50 \pm 36.427^{\mathrm{a}}$ & $120.50 \pm 53.435$ \\
\hline
\end{tabular}

Non-significant $(p>0.05)$, significant $(p<0.05)$

aControl with pre-treatment

${ }^{\mathrm{b}}$ Pre-treatment with post-treatment

${ }^{\circ}$ Control with post-treatment

TP: Total Protein; TC: Total Cholesterol; TG: Triglyceride; AST: Aspartate Transaminase; ALT: Alanine Transaminase; LDH: Lactate Dehydrogenase; CK: Creatine Kinase

Table 2: In vivo effect of methyldopa on laboratory findings.

TP, urea, TC, TG, AST, ALT and CK). Creatinine was not affected, and LDH was with elevated readings with high drug doses.

The in vivo work measures the drug interferences with the quantity to be measured under physiological conditions. The proposed mechanism can be more diverse, especially with the knowledge that some drugs can cause induction of hepatic microsomal enzymes, a normal pharmacological response of a normally functioning liver. Hence, the in-vivo response to a drug depends on the patient, on the drug type and dosage and on whether other medications are being taken concurrently. The experimental design compared the concentrations of the biochemical parameters in patients before and after treatment. That set-up should enable the researcher to measure for the effects of the drugs on the biochemical parameters. Consequently, and following methyldopa consumption for two weeks, the only significant alteration obtained was that with Total Protein (TP) when comparing the prewith the post-treatment measurements. There are two explanations for this. The first direct explanation would be that methyldopa is interfering, chemically or physically with the assay. Alternatively, it may be explained on the basis of a genuine rise in the TP following the control of the elevated blood pressure, as that may allow a rise in the intra-vascular oncotic pressure. Moreover, on comparing the posttreatment sera with the controls, their readings of TC, TG and AST and in the LDH were significantly higher. The enzymes elevations may be due to hepatic enzyme induction. Yet the rise of the TC and TG rise may be genuine, since the pre-treatment levels had been high compared with the controls. Such elevated TC and TG levels would be rather expected in the sera of hypertensive patients as a normal physiological effect or may due to a high oxidative stress in hypertensive patients [10,11].

The glucose findings have been in agreement with previously published data on the rise of glucose with methyldopa therapy, with a possible relation with the methods used $[12,13]$. With standardized methods, the effects of drugs on glucose level may decrease in vitro assays, whereas they would increase during the in vivo study. Such a controversy would probably be due to metabolic effects or due to interaction of the drugs or their metabolites.

Creatinine and urea levels were insignificantly increased with methyldopa therapy, in agreement with previous records $[14,15]$. Creatinine increment due to methodological effects such as being readily oxidized in the Alkaline picrate method and Fuller's earth procedures [16-19], indicate that methyldopa may interfere with the
Jaffe reaction. Hence, these analytical interferences are due to chemical interferences of the drug with the analytical methods used [20].

Serum AST, ALT, LDH and CK levels were not significantly increased with methyldopa therapy as compared to the pre-treated patients and are generally in agreement with previous reports [21,22] These alterations in the serum AST and ALT concentrations may be due to cholestatic effects [14], or due to some hepatotoxicity [19]. However, elevations in the CK levels can be expected since myocarditis has previously been associated with methyldopa therapy in several patients, with concurrent rises in CK $[22,23]$.

With more drugs becoming available every year, many of which are extremely potent, the chances of more adverse drug reactions are multiplied. Knowledge of these alterations may be necessary for assessing the findings in patients receiving these medicines. The effects of drugs on laboratory tests are not negligible, especially that a great number of drugs' effects have been reported [24,25], and that approximately $12 \%$ of patients have their laboratory results affected by drugs in the general medical field [25]. Ultimately, the effects of drug additives cannot be completely excluded.

Knowledge of any aberrations in the results of laboratory determinations caused by drugs should be made clear to avoid misinterpretation of data and any possible unwanted consequences in the management and/ or outcomes of diagnoses and therapies.

In conclusions, physicians need to be alerted to alterations induced by drugs and clinical biochemists, as well as clinical pharmacists to be able to consider proper interpretations of laboratory results, particularly when more than one drug is used. The results presented in this study demonstrated clearly that laboratory findings are altered by methyldopa. They may be due to chemical and physical interferences. In the in vivo findings, the changes in concentration of metabolites and enzymes may be explained, in part, by the pharmacodynamic characteristics of the drug, in addition to physical and chemical factors.

\section{Acknowledgment}

The authors would like to express their gratitude to the College of PharmacyBaghdad University, for allowing this work to be performed, and to Dr. Hilal B. AL Saffar, the cardiology specialist at Dr. Abdul-Majeed Hospital, Karradah, Baghdad Thanks are also to all the study subjects (patients and controls) who participated willingly in this work.

\section{References}

1. Onesti G, Brest AN, Novack P, Moyer JH (1962) Pharmacodynamic effects and clinical use of alpha methyldopa in the treatment of essential hypertension. Am J Cardiol 9: 863-867.

2. Evans RG (1996) Current status of putative imidazoline (I1) receptors and rena mechanisms in relation to their antihypertensive therapeutic potential. Clin Exp Pharmacol Physiol 23: 845-854.

3. British Pharmacopoeia (1993) IA: 55.

4. Harper ML (2011) Martindale: the complete drug reference. 37th edn, Ann Pharmaother.

5. Phycian's GenRx (1996) The Complete Drugs Reference. Mosby, New York pll 157-159.

6. César Ida C, Byrro RM, Cardoso FF, Mundim IM, Teixeira Lde S, et al. (2011) Simultaneous quantitation of levodopa and 3-O-methyldopa in human plasma by HPLC-ESI-MS/MS: application for a pharmacokinetic study with a levodopa/ benserazide formulation. J Pharm Biomed Anal 56: 1094-1100.

7. Wolf WA, Bobik A (1989) alpha-Methyldopa metabolism in central serotonergic nerve terminals: effects on serotonin levels, synthesis and release. Eur $J$ Pharmacol 163: 43-53

8. Chatelain P, Waelbroeck M, Camus JC, De Neef P, Robberecht P, et al. (1981) Comparative effects of alpha-methyldopa, propranolol and hydralazine therapy 
Citation: Ibrahim IAA, Shahzad N, Al-Joudi FS, Al-Ghamdi SS, Alshagga MA, et al. (2013) In vitro and In vivo Study of Effect of a-Adrenergic AgonistMethyldopa on the Serum Biochemical Laboratory Findings. Clin Exp Pharmacol 3: 136. doi:10.4172/2161-1459.1000136

on cardiac adenylate cyclase activity in normal and spontaneously hypertensive rats. Eur J Pharmacol 72: 17-25.

9. Wright LA, Foster MG (1980) Effect of some commonly prescribed drugs on certain chemistry tests. Clin Biochem 13: 249-252.

10. Kroll MH, Elin RJ (1994) Interference with clinical laboratory analyses. Clin Chem 40: 1996-2005

11. Parik T, Allikmets K, Teesalu R, Zilmer M (1996) Evidence for oxidative stress in essential hypertension: perspective for antioxidant therapy. J Cardiovasc Risk 3: 49-54.

12. Lacy F, O'Connor DT, Schmid-Schönbein GW (1998) Plasma hydrogen peroxide production in hypertensives and normotensive subjects at genetic risk of hypertension. J Hypertens 16: 291-303.

13. Helgeland A, Leren P, Foss OP, Hjermann I, Holme I, et al. (1984) Serum glucose levels during long-term observation of treated and untreated men with mild hypertension. The Oslo study. Am J Med 76: 802-805.

14. Caraway WT, Kammeyer CW (1972) Chemical interference by drugs and othe substances with clinical laboratory test procedures. Clin Chim Acta 41: 395434.

15. Singh HP, Hebert MA, Gault MH (1972) Effect of some drugs on clinical laboratory values as determined by the Technicon SMA 12-60. Clin Chem 18: 137-144.
16. Constantino NV, Kabat HF (1973) Drug-induced modifications of laboratory test values--revised 1973. Am J Hosp Pharm 30: 24-71.

17. Fletcher AE (1991) Adverse treatment effects in the trial of the European Working Party on High Blood Pressure in the Elderly. Am J Med 90: 42S-44S.

18. Martin EW (1971) Hazards of medications a manual on drug interactions incompatibilities, contraindications and adverse effect. Lippincott, Philadelphia, PA.

19. Maddocks J, Hann S, Hopkins M, Coles GA (1973) The effect of methyldopa on creatinine estimation. Lancet 1: 157.

20. Routh JI, Paul WD (1976) Assessment of interference by aspirin with some assays commonly done in the clinical laboratory. Clin Chem 22: 837-842.

21. USP (1995) Drug information for health care professional. 15th edn, Roud McNally, Taunton MA, USA

22. Cacace LG, Cohen M (1976) Alpha-methyldopa (aldomate) hepatitis: report of a case and review of the literature. Drug Intell Clin Pharm 10: 144

23. Mullick FG, McAllister HA (1977) Myocarditis associated with methyldopa therapy. JAMA 237: 1699-1701.

24. Young DS (1995) Effects of drugs on clinical laboratory tests. 4th edn Washington, AACC.

25. Hansten PD (1979) Drug Interactions. Lea and Febiger. Philadelphia: 301-491. 